\title{
Reconstructive Trends in Post-Ablation Patients with Esophagus and Hypopharynx Defect
}

\author{
Sae Hwi Ki, ${ }^{1,2}$, \\ Jong Hwan $\mathrm{Choi}^{2}$, \\ Seung Hyun $\mathrm{Sim}^{3}$ \\ ${ }^{1}$ Department of Plastic Surgery, Inha \\ University School of Medicine, Incheon; \\ ${ }^{2}$ Department of Plastic Surgery, \\ Inha University Hospital, Incheon; \\ ${ }^{3}$ Inha University Hospital, Incheon, Korea
}

No potential conflict of interest relevant to this article was reported.

\begin{abstract}
The main challenge in pharyngoesophageal reconstruction is the restoration of swallow and speech functions. The aim of this paper is to review the reconstructive options and associated complications for patients with head and neck cancer. A literature review was performed for pharynoesophagus reconstruction after ablative surgery of head and neck cancer for studies published between January 1980 to July 2015 and listed in the PubMed database. Search queries were made using a combination of 'esophagus' and 'free flap', 'microsurgical', or 'free tissue transfer'. The search query resulted in 123 studies, of which 33 studies were full text publications that met inclusion criteria. Further review into the reference of these 33 studies resulted in 15 additional studies to be included. The pharyngoesophagus reconstruction should be individualized for each patient and clinical context. Fasciocutaneous free flap and pedicled flap are effective for partial phayngoesophageal defect. Fasciocutaneous free flap and jejunal free flap are effective for circumferential defect. Pedicled flaps remain a safe option in the context of high surgical risk patients, presence of fistula. Among free flaps, anterolateral thigh free flap and jejunal free flap were associated with superior outcomes, when compared with radial forearm free flap. Speech function is reported to be better for the fasciocutaneous free flap than for the jejunal free flap.
\end{abstract}

Keywords: Esophagus / Reconstruction / Free tissue transfer / Cancer / Review

\section{INTRODUCTION}

Despite improvements in chemotherapy and chemoradiotherapy, ablative surgery remains an important therapeutic option in the management of hypopharyngeal and esophageal cancer. After ablative surgery, the surgeon is faced with the need to reconstruct the digestive conduit for swallowing and speech. There are many options for the reconstruction of hypopharnyx and esophagus according to the amount of defect such as partial or circumference defect of the esophagus and accompanying surrounding soft tissue defect. However, no review comparing the complication rates of each reconstruction flap has been reported.

Correspondence: Sae Hwi Ki

Department of Plastic Surgery, Inha University School of Medicine, 27 Inhang-ro, Jung-gu, Incheon 22332, Korea

E-mail:mdki67@naver.com

Received August 25, 2015 / Revised October 13, 2015 / Accepted October 14, 2015
Before the microsurgical techniques, pedicled flaps for reconstruction of esophagus defects have been used for decades and multiple staged procedures were sometimes required. Pedicled flaps are often bulky and have poor skin color match and significant donor-site morbidity in the functional and aesthetic aspect. Recently, free tissue transfers for reconstruction of the esophagus reconstruction are being used in several medical centers. However, the choice of the best reconstructive option for reconstruction is still controversial because of the difficulty in microsurgical technique, complication rates, flap failure rates, defect type, and patient comorbidity, and biases are encountered in direct comparison between one method and another.

We review recent articles and compare the most frequently used reconstructive options available, in order to choose the surgical option for reconstruction of the esophagus, according to the condition of the patient, defect of the esophagus, amount of the sur- 
rounding tissue defect, complication rate, and other conditions.

\section{METHODS}

A literature review was performed for pharynoesophagus reconstruction after ablative surgery of head and neck cancer for studies published between January 1980 to July 2015 and listed in the PubMed database. Search queries were made using a combination of 'esophagus' and 'free flap', 'microsurgical', or 'free tissue transfer'. The inclusion criteria were as follows: involving human subjects, published in the English language, head and neck cancer reconstruction, reconstruction with pedicled flap, fasciocutaneous free flap, jejunal free flap, and clinical studies. Publications were excluded for animal studies, cases of esophageal cicatrical stricture, gastric pull-up (GPU) procedure, and non-English publications. In addition, supplemental hand searches were performed of bibliographies of relevant papers, and extensive "related articles". The title and abstract of all identified studies were examined by two independent reviewers. In cases where suitability of a study for inclusion in the review was uncertain, the entire paper was reviewed and assessed. Articles were classified according to pedicled flap, fasciocutaneous free flap, jejunal (visceral) free flap, and comparison between several types of flap.

\section{RESULTS}

The search query identified 123 publication, of which 54 articles were available in the full text form. Twenty one studies were excluded following review of the title and abstract. The entire manuscripts of the remaining 33 articles were reviewed to determine suitability for inclusion. Review of the references in these 33 articles yielded 14 more studies to be included for a total of 48 studies.

Among these 22 papers had reported on complication rates following esophageal reconstruction. There were 7 papers on pectoralis major myocutaneous flap, 5 papers on radial forearm free flap (RFFF), 4 papers on anterolateral thigh (ALT) free flap, and 12 papers on jejunal free flap. Papers on complications of the other flaps were checked under 3 papers.

\section{DISCUSSION}

Pharyngoesophageal defects result from the ablation of malignant tissues involving the larynx and hypopharynx. The circumference or partial defect of the esophagus and the morbidity associated with an oropharyngeal-cutaneous fistula after ablative surgery requires flap reconstruction in order to restore pre-malignancy functions. For many years, reconstructive surgeons have used pedicled flaps or free flaps, with each individual technique having its own advantages and disadvantages. The choice of technique is dependent on factors such as extent of local invasion, the general medical condition of patient, the risk of the complication, and the experience of the surgical team and the available facilities. The ideal reconstruction involves re-creation of a digestive conduit with vascularized tissue that enables early restoration of swallowing and speech while minimizing complications such as fistula, stricture, anastomotic site leakage, or flap necrosis. In addition, single stage reconstructions are preferred for minimal morbidity and mortality [1].

Local flaps are often of inadequate size, and pedicled flaps are bulky and often associated with significant donor-site morbidity. Microsurgical free flaps are ideal but require technical expertise and longer operative time. Although free flap reconstruction (e.g., jejunum and fasciocutaneous flaps) is considered the standard of care of this complex defect, regional flaps are still in use worldwide [2].

\section{Choosing an appropriate flap}

The method of reconstruction depends on a patient's state of health, the length and width of mucosal defect, presence of fistulas, history of radiation, previous operations, and flap availability. High-risk patients are not always acceptable surgical candidates for potentially prolonged microsurgery. Because of these potentially limiting factors, pedicled flaps remain the preferred technique [3].

\section{Pedicled flaps}

Bakamjian [4] first described a deltopectoral flap as an axial flap. More recently, pedicled flaps such as the pectoralis major myocu- 
taneous flap (PMMC), submental flap, trapezius myocutaneus flap, sternocleidomastoid musculocutaneous flap, and supraclavicular flaps have been used for esophagus reconstruction [5].

Pedicled flaps have disadvantages of limited arc of rotation and a tissue bulkiness. However, pedicled flaps are still used for the shorter operative time and comparatively lower risk of operative and postoperative complications when compared to free flap transfers. Although the tissue bulkiness may result cosmetically suboptimal, the volume can be very useful for coverage of major vascular structures and obliteration of deep cavities [6].

\section{PMMC pedicled flap}

The PMMC pedicled flap was introduced by Ariyan [7] in 1979 for reconstruction of circumferential hypopharyngeal defects. The flap has been used in reconstruction of head and neck defects, including the tongue, mandible, oropharynx, and esophagus [8].

Advantages of the PMMC flap include easy harvest technique,

Table 1. Complication rates in pectoralis major myocutaneous flap

\begin{tabular}{lccccccccc} 
& \multicolumn{1}{c}{ PMMC } \\
\cline { 2 - 8 } Reference number & {$[1]$} & {$[3]$} & {$[8]$} & {$[9]$} & {$[19]$} & {$[34]$} & {$[48]$} & \\
\hline Fistula (\%) & $4-47$ & - & 27 & 4 & 27 & - & $13-78$ & 54 \\
\hline Stricture (\%) & $6-16$ & - & 18 & 2 & 17 & 17 & $12-27$ & 14.4 \\
\hline Flap loss/Necrosis (\%) & - & N/6 & - & N/0 & $0.5 / N$ & - & - & - \\
Anastomotic leak (\%) & - & 11 & 9 & - & - & - & - & - \\
\hline Hematoma (\%) & - & - & 0 & - & - & 11 & - & - \\
Seroma (\%) & - & - & 0 & - & - & - & - & - \\
\hline Infection (\%) & - & - & - & - & 10 & 11 & - & - \\
\hline
\end{tabular}

PMMC, pectoralis major myocutaneous flap; $\mathrm{N}$, none relatively short operative times, and the lack of requirement for microvascular anastomosis. However, complication rates for fistula formation, stricture rate, and anastomotic site leakage are higher for this flap when compared to the RFFF, ALT, and jejunal free flap (Table 1) [9]. Mean fistula formation rate was 54\% (range, 0\%-78\%) for PMMC flaps, with a mean stricture rate of $14.4 \%$ (range, $2 \%$ 27\%). Perioperative mortality was less than $1 \%$, and the success rate is quite high.

Currently, this flap should be considered as a second-line reconstruction option, limited to partial hypopharyngeal defects in patients with significant comorbidities. In addition, this flap can be suitable for prior free flap failure or for pharyngocutaneous fistulas from preoperative radiation as a simultaneous flap used to reinforce the suture lines and vital structures with an additional coverage [10].

\section{LDMC flap}

The pedicled latissimus dorsi myocutaneous flap (LDMC) is still used for reconstruction of esophagus after ablation of head and neck carcinoma [11]. It has several advantages, including a wider arc of rotation, larger flap dimensions, a reliable vascular pedicle, sufficient muscle padding for protection of vital organs, and a hairless skin island as with PMMC. It can be changed as a free flap in cases where difficulty arises during the pedicled flap procedure $[11,12]$. However, the flap is too thick to be warped into a tubed conduit, requires re-positioning of the patient, and can result in shoulder stiffness and seroma. Fistula and flap necrosis rates range $6 \%-20 \%$ and $9 \%-20 \%$, respectively (Table 2 ).

Table 2. Complication rates in other pedicled flaps

\begin{tabular}{|c|c|c|c|c|c|c|c|c|c|c|c|c|c|c|c|}
\hline \multirow[t]{2}{*}{ Reference number } & \multicolumn{3}{|c|}{ Gastric pull-up } & \multicolumn{2}{|c|}{ LDMC } & \multicolumn{2}{|c|}{ TADP } & \multicolumn{2}{|c|}{$\begin{array}{l}\text { Supraclavicular } \\
\text { flap }\end{array}$} & \multicolumn{2}{|c|}{ Ileocolon flap } & \multicolumn{2}{|c|}{$\begin{array}{l}\text { Gastro-omental } \\
\text { free flap }\end{array}$} & \multirow{2}{*}{$\begin{array}{c}\begin{array}{c}\text { Colon } \\
\text { interposition }\end{array} \\
{[1]}\end{array}$} & \multirow{2}{*}{$\frac{\text { SCM }}{[6]}$} \\
\hline & {$[1]$} & [3] & {$[48]$} & [12] & [13] & [15] & {$[18]$} & {$[16]$} & {$[17]$} & [45] & [48] & [19] & {$[31]$} & & \\
\hline Fistula & $17-27$ & - & $3-48$ & 6 & 20 & - & - & - & 16 & - & $8-46$ & 16 & 67 & - & - \\
\hline Stricture & - & - & $0-29$ & - & - & - & - & - & - & 57 & - & 22 & 17 & - & - \\
\hline Flap loss/Necrosis & - & $\mathrm{N} / \mathrm{O}$ & - & $1 / 9$ & $10 / 20$ & $3 / \mathrm{N}$ & $\mathrm{O} / \mathrm{N}$ & $6 / 6$ & $4 / 18$ & $\mathrm{~N} / 7$ & - & $\mathrm{O} / \mathrm{N}$ & $0 / 17$ & $\mathrm{~N} / 5-31$ & $N / 21-66$ \\
\hline Anastomotic leak & - & 9 & - & - & - & - & - & 17 & - & 34 & - & - & - & $9-11$ & - \\
\hline Hematoma & - & - & - & 3 & - & - & - & - & 7 & - & - & - & - & - & - \\
\hline Seroma & - & - & - & - & - & 0 & 0 & - & 4 & - & - & - & - & - & - \\
\hline Donor complication & - & - & - & - & - & - & 12.5 & 6 & 13 & - & - & 13 & - & - & - \\
\hline Infection & - & - & - & - & 10 & - & - & 11 & 4 & - & - & - & - & - & - \\
\hline
\end{tabular}

LDMC, pedicled latissimus dorsi myocutaneous flap; TADP, pedicled thoracodorsal artery perforator flap; SCM, pedicled sternocleidomastoid muscle flap; N, none. 


\section{TDAP flap}

The thoracodorsal artery perforator (TDAP) flap is the perforator version of the pedicled latissimus dorsi myocutaneous flap [13]. Various anatomic and clinical studies have explored the advantages of pedicled TDAP flap for coverage of wounds on the anterior chest wall, clavicle, axilla, and the proximal arm $[14,15]$. This flap has advantages in overcoming the unfavorable flap thickness of the LDMC and shoulder stiffness. Very low complication rates have been reported for this flap (Table 2).

\section{The sternocleidomastoid myocutaneous flap}

The sternocleidomastoid myocutaneous flap is ideal for "patch" esophagoplasty in patients who do not have circumferential defects. The flap is smaller than PMMD and LDMC. The flap has found many successful applications, such as closure of orocutaneous fistula, pharyngocutaneous and cervical esophageal fistulae, reconstruction of the tongue and oral cavity defects, and reconstruction of cervical esophageal strictures [6].

Advantages of this flap include minimal morbidity, no functional loss, minimal cosmetic deformity, and primary closure of the donor site. However, flap necrosis are reported in the range of 20\%-to-66\%.

\section{The supraclavicular artery flap}

The supraclavicular artery flap is an axial flap taken from the shoulder and supraclavicular area. This flap was used in reconstruction of ablative defects of head and neck cancer in critical locations such as the pharyngeal wall, radiated neck, tracheal-stomal junction, mandible, and the parotid gland.

The pedicle of this flap is a distinct branch of the transverse cervical artery in most cases and, infrequently, of the suprascapular artery $[16,17]$. Chiu et al. [16] reported the initial experience with the supraclavicular artery island flap for reconstruction of oncologic defects of the head and neck, and his group has reported extensively on reliability and versatility. Pallua et al. [18] reported that flaps of 4 to $12 \mathrm{~cm}$ in width and 20 to $30 \mathrm{~cm}$ in length can be harvested safely.

The supraclavicular artery flap has several advantages including simple and easy harvesting, thin and pliable skin flap, excellent col- or matching, sufficient length for reconstruction of esophagus, useful for augmentation of the pharyngeal closure after total laryngectomy, and minimal donor-site morbidity $[16,17]$. However, this flap has a limited arc of rotation and inadequate vascularity in smokers and patients with multiple medical comorbidities $[16,17]$. Fistula and anastomotic leakage rates are reported to be $16 \%$ and $17 \%$, respectively. Flap loss rates are reported at 4\%-to-6\% (Table 2).

\section{The submental flap}

The submental flap is a quick and easy method of reconstructing smaller circumferential defects with low morbidity and excellent functional results. Such situations are encountered in patients who received extensive preoperative irradiation, have multiple preoperative morbidities, and present at an advanced stage of the disease. This flap measures $18 \mathrm{~cm} \times 6 \mathrm{~cm}$ and is often too thin or too small for larger pharyngeal or esophageal defects [5].

\section{Free flaps}

There is no universal agreement on the optimal method of free flap reconstruction for esophageal defects. The RFFF, the ALT free flap, and the jejunal free flap are the most popular methods. In addition, other fasciocutaneous free flaps have been used for esophagus reconstruction, such as rectus abdominis, ulnar forearm, lateral arm, parascapular, tensor fasciae latae, lateral thigh, posterior tibial, and peroneal flap [19-22].

Fasciocutaneous flaps provide versatile, reliable, and well-vascularized tissue to post-ablation pharynx and esophagus, which frequently have poor vascularity due to radiotherapy or chemoradiotherapy. Free-tissue transfer requires technical expertise, longer operative times, and extensive postoperative monitoring. Operative time is somewhat long, but surgical time can be shortened considerably by using a two-team approach. According to several reports, the jejunal free flap and fasciocutaneous free flap had similar complication rates. However, even a partial flap loss may be a seriorus complication in the field of pharyngoesophageal reconstruction surgery [3,23]. Many surgeons prefer to use the jejunal free flap for total esophagus reconstruction, as it is a naturally tubed conduit. However, the donor site morbidity is often a deter- 
rent for many others. Both RFFF and ALT flaps can be tubed as a circumferential with a linear suture line $[23,24]$.

\section{The radial forearm free flap}

The RFFF was introduced by Yang et al. [25] and was first applied in its "circumferential fabricated" form in 1985 [26]. To be used in its tubed form, the flap is modified with edge-deepithelialization with two-layered sutures to significantly reduce salivary leakage [2,27,28]. This technique is still widely applied for use in radial forearm after circumferential resections, whereas for partial reconstruction of less than $50 \%$ of the esophagus RFFF is applied in its 'patch' form. Perioperative mortality is exceedingly rare. However, studies have reported poor donor-site aesthetic outcomes, partial or total loss of the skin graft, tendon exposure, cold intolerance (especially in winter), and transient or permanent numbness of the thumb [19,22]. In this review, fistula and stricture rates were higher for the RFFF than those of the ALT and jejunal free flap (Tables 3-5).

Table 3. Complication rates in RFFF

\begin{tabular}{|c|c|c|c|c|c|c|c|}
\hline \multirow{2}{*}{ Reference number } & \multicolumn{6}{|c|}{ RFFF } & \multirow{2}{*}{ Mean } \\
\hline & [1] & [19] & [24] & [27] & [28] & [48] & \\
\hline Fistula & $17-28$ & 20 & 20 & 38 & - & - & 24.9 \\
\hline Stricture & $10-36$ & 11 & 10 & 39 & - & 18 & 24.8 \\
\hline Flap loss/Necrosis & - & $2 / \mathrm{N}$ & $\mathrm{N} / \mathrm{O}$ & $8 / 3$ & $4 / 6$ & - & - \\
\hline Hematoma & - & - & - & - & 0 & - & - \\
\hline Donor complication & - & 9 & - & - & - & - & - \\
\hline Infection & - & - & - & 3 & - & - & - \\
\hline
\end{tabular}

RFFF, radial forearm free flap; $\mathrm{N}$, none

Table 5. Complication rates in jejunal free flap

\begin{tabular}{|c|c|c|c|c|c|c|c|c|c|c|c|c|c|}
\hline \multirow{2}{*}{ Reference number } & \multicolumn{12}{|c|}{ Jejunal free flap } & \multirow{2}{*}{ Mean } \\
\hline & [1] & [3] & {$[19]$} & [23] & [27] & [28] & [39] & [40] & {$[41]$} & [42] & {$[47]$} & {$[48]$} & \\
\hline Fistula & 8-22 & - & 12 & 3 & 4 & - & - & 10 & 7 & 10 & 8 & $0-32$ & 10.5 \\
\hline Stricture & $15-22$ & - & 11 & 19 & 9 & - & - & 10 & 23 & 7 & 11 & - & 14.2 \\
\hline Flap loss/ necrosis & - & $\mathrm{N} / 5.4$ & $4 / \mathrm{N}$ & $6 / N$ & $9 / 7$ & $17 / 33$ & $\mathrm{O} / \mathrm{N}$ & $0 / 3$ & $\mathrm{O} / \mathrm{N}$ & - & $3 / \mathrm{N}$ & $10 / N$ & - \\
\hline Anastomotic leak & - & 8 & - & 3 & - & - & - & - & - & - & - & - & - \\
\hline Hematoma & - & - & - & 3 & 1 & - & - & - & - & - & - & - & - \\
\hline Seroma & - & - & - & - & - & 0 & 0 & - & - & - & - & - & - \\
\hline Donor complication & - & - & 3 & - & - & - & 12.5 & - & - & - & - & - & - \\
\hline Infection & - & - & - & 3 & 4 & - & - & - & - & - & - & - & - \\
\hline
\end{tabular}

$\mathrm{N}$, none.

\section{$A L T$ free flap}

The anterolateral thigh (ALT) free flap was described by Song et al. [26] in 1984. Among various fasciocutaneous flaps, this flap has become an important alternative to the radial forearm for esophageal reconstruction. The flap can be used in its tubed or conical form for circumferential defects of the pharyngoesophagus and can be used in the "patch" form for partial defects [5].

The ALT flap has several advantages. It is versatile and has a large skin surface and can be tailored including variable amounts of muscle, fat, or fascia. Extensive portions of the vastus lateralis muscle can be taken together, which can be used to protect the suture line of the esophagus and the great vessels after sternocleidomastoid muscle removal. The pedicle length of the ALT free flap is sufficient to reach the vessels of the head and neck defect. Perioperative mortality is extremely rare for the ALT free flap transfer, and donor-site morbidity is very low amongst various the free flap options for esophageal reconstruction [5]

In a recent comparison between free jejunum and ALT flaps for

Table 4. Complication rates in ALT

\begin{tabular}{|c|c|c|c|c|c|}
\hline \multirow{2}{*}{ Reference number } & \multicolumn{4}{|c|}{ ALT } & \multirow{2}{*}{ Mean } \\
\hline & [1] & [19] & [23] & [48] & \\
\hline Fistula & $0-13$ & 15 & 8 & - & 9 \\
\hline Stricture & $12-27$ & 9 & 15 & 11 & 14.8 \\
\hline Flap loss/ necrosis & - & $2 / \mathrm{N}$ & $4 / 40$ & - & - \\
\hline Anastomotic leak & - & - & 4 & - & - \\
\hline Hematoma & - & - & 4 & - & - \\
\hline Donor complication & - & 7 & - & - & - \\
\hline Infection & - & - & 4 & - & - \\
\hline
\end{tabular}

ALT, anterolateral thigh free flap; $\mathrm{N}$, none 
reconstruction of circumferential defects, the ALT reconstruction was associated with improved speech and swallowing functions as well as shorter intensive care and hospital stays. Complications after ALT flap reconstructions include the incidence of fistula, with rates similar to those of the jejunal free flap (Tables 3,4) [2,29].

\section{Visceral free flaps}

\section{The Jejunal free flap}

There are many surgical options based on visceral free flaps, from the GPU and colic transposition to jejunal and gastro-omental free flap. The jejunal free flap is a highly popular reconstructive option at many microsurgical centers since it was first used in 1958 by Seidenberg et al. [30]. Some surgeons strongly believe that the jejunal free flap is the best option for the swallowing function.

The concept of a tubed graft, which involves anastomosis of the neo-esophagus to the oropharynx superiorly and to the distal esophageal stump inferiorly, seemed an ideal reconstructive tool. However, the jejunal free flap is associated with serious complications such as bowel obstruction, intraabdominal bleeding, acute gastric dilatation, hernia, superior mesenteric syndrome, and ileus [19]. Another potential, but questionable, disadvantage of this flap is the limited ischemic tolerance of the jejunum, with consequently shorter ischemia time available for microvascular anastomoses and potential alterations of the graft mucosal lining, thus predisposing the flap to partial flap loss $[2,19]$.

The jejunal free flap should be an ideal option, as there is no vertical suture line, fistula formation may be less and patients have an excellent chance of resuming an oral diet. According to many reports, however, fistula formation after jejunal free flap reconstruction is reported with rates comparable to fistula formation after fasciocutaneous free flap $[2,3]$.

The tracheoesophageal prosthesis placement during the additional surgery results in an acceptable voice. Nevertheless, many reports have shown that the voice quality after reconstruction with the jejunal free flap is also associated with a "wet" voice [2].

\section{The gastro-omental free flap}

Gastro-omental free flap is yet another option for the pharyngoe- sophageal reconstruction. This flap can be up to $30 \mathrm{~cm}$ long with suitable pedicle calibers $(2-4 \mathrm{~mm})$ for microanastomosis. In addition, the greater omentum provides a generous amount of highly vascularized tissue to be draped around the neoesophagus conduit, as a protective wrap, covering the great vessels and filling every dead space $[31,32]$. Unfortunately, very high complication rates were reported for the ileocolon flap, gastro-omental flap, and colon interposition (Table 2).

\section{Methods to improve the survival rate of flaps and to reduce complications}

\section{Pedicled flaps}

Pedicled flaps are often thick and are difficult to contour for esophagus reconstruction. In a partial esophageal defect, the partially tubed PMMC forms the anterior and lateral walls of the neoesophagus, with the posterior wall of the reconstruction anchoring to prevertebral fascia [2]. In a circumferential esophageal defect, the esophagus is reconstructed by folding the skin island and suturing it to the base of the tongue and posterior wall superiorly and to the cervical esophageal stump inferiorly. Modified forms include 'U-shaped', 'omega-shaped', or 'horseshoe-shaped' reconstructions $[19,33,34]$.

\section{Fasciocutaneous free flaps}

Pierrel describes a pharyngeal reconstruction with semi-free forearm flap, pedicled on the cephalic vein, to minimize the risk of venous thrombosis [35]. In a complex soft tissue defect, the reconstruction of both the esophagus and anterior neck skin requires multiple flaps. A free flap had been designed in a "tube-in-a-tube" fashion or in a Chimeric pattern for simultaneous reconstruction of the complex cervical esophagus [36]. With RFFF for reconstruction of the esophagus, cervical anastomotic leakage was prevented with on-lay vascularized muscle flaps [37].

\section{Visceral free flaps}

Many researchers have reported no differences in functional or oncological outcomes in comparing jejunal free flap to fasciocutaneous free flaps $[2,3,38,39]$. However, there are many efforts to 
decrease complications such as esophagocutaneous fistula [40,41]. According to certain reports on prevention or minimizing fistula and stricture, novel approaches have been reported to be safe and effective. Examples include gastrointestinal stapler for bowel anastomosis or prophylactic use of a PMMC in patients with history of radiotherapy $[2,40,42]$.

Chang et al. [43] described prefabrication of the jejunum in LD muscle in a patient with multiple tracheoeosphageal fistulas. As esophageal resections extend to be superior, there may be size discrepancy between the proximal jejunum and the pharygostome, described as the inverted, stapled J-pouch free jejunal transfer to overcome the size discrepancy, analogous to that used in the ileoanal anastomosis after proctocolectomy for treatment of ulcerative colitis [44].

Perrone reported that the extra length of jejunum was very useful in widening the upper portion of the esophagus with a prefabricated flap, for creation of a seromuscular flap for prevention of leakage, for creation of a simultaneous free jejunal diversionary conduit and a separate pharyngo-cutaneous fistula [45]. The Ileocoleic free flap is useful for the simultaneous restoration of swallowing and voice production $[44,46]$.

\section{A comparison of reconstructive methods}

In the wider literature, the rate of free flap necrosis ranges are reported from $2 \%$ to $10 \%$ [47]. In our review, flap necrosis rates were particularly high in latissimus dorsi myocutaneous flap, supraclavicular flap, ileocolon flap, gastro-omental flap, colon interposition, and sternocleidomastoid myocutaneous flap (Table 2).

The GPU, pedicled flap, and free flap are effective for reconstruction of the hypopharynx and esophagus. Similar complication rates have been reported $[2,48]$. Several series have reported reconstructions of the pharyngoesophagus using GPU with mortality and morbidity rates ranging from 5\% to $31 \%$ and from $5 \%$ to $55 \%$, respectively $[3,47]$. Pulmonary complications were frequent after GPU [48].

Free flaps provide excellent aesthetic and functional outcomes. Favorable operative factors include robust blood supply, versatility for orientation and insetting the flap, and usefulness in many dif- ferent types of tissue. However, multiple free flaps are required for simultaneous reconstruction of both esophagus and skin [3].

With the jejunal free flap, several studies have reported low morbidity and mortality rates and good functional outcomes, with successful reconstruction of the esophagus in approximately $95 \%$ of patients [3].

\section{CONCLUSION}

There is no single ideal reconstructive option for pharyngoesophageal defects after tumor resection. The PMMC flap and other pedicled flaps in modified forms remain first-line choices in high co-morbidity patients, and are appropriate following fistula formation in previous radiotherapy.

For partial esophageal defects, no specific flap is deemed superior over others. Surgeon preference, expert option, and individual patient condition are the most important factors affecting the reconstructive choice. Both ALT and RFFF remain popular. Although complication rates differ across studies, stricture and fistula rates of the RFFF might be higher than those for the ALT and jejunal free flap due to partial flap loss.

For circumferential esophagus reconstruction, fistula and stricture rates were higher for RFFF than for free flaps. At most institutions, the jejunal free flap is considered as an ideal option for esophagus reconstruction. In the most recent studies, ALT and jejunum fistula had similar rates for stricture occurrence, mortality, and overall complication. However, donor-site morbidity, swallowing, and speech outcomes were superior for ALT than for jejunal free flap.

\section{REFERENCES}

1. Richmon JD, Brumund KT. Reconstruction of the hypopharynx: current trends. Curr Opin Otolaryngol Head Neck Surg 2007;15:208-12.

2. Nagel TH, Hayden RE. Advantages and limitations of free and pedicled flaps in reconstruction of pharyngoesophageal defects. Curr Opin Otolaryngol Head Neck Surg 2014;22:407-13.

3. Elfeky AE, Nasr WF, Khazbak A, Abdelrahman MS, Allam ZA, Gareer WY, et al. Hypopharyngeal reconstruction: a comparison of three alternatives. Eur Arch Otorhinolaryngol 2015;272:3045-50.

4. Bakamjian VY. A two-stage method for pharyngoesophageal reconstruction with a primary pectoral skin flap. Plast Reconstr Surg 1965; 36:173-84. 
5. Welkoborsky HJ, Deichmuller C, Bauer L, Hinni ML. Reconstruction of large pharyngeal defects with microvascular free flaps and myocutaneous pedicled flaps. Curr Opin Otolaryngol Head Neck Surg 2013;21:318-27.

6. Noland SS, Ingraham JM, Lee GK. The sternocleidomastoid myocutaneous "patch esophagoplasty" for cervical esophageal stricture. Microsurgery 2011;31:318-22.

7. Ariyan S. The pectoralis major myocutaneous flap: a versatile flap for reconstruction in the head and neck. Plast Reconstr Surg 1979;63:73-81.

8. Burke MS, Kaplan SE, Kaplowitz LJ, Lotempio MM, Hicks WL Jr, Rigual NR, et al. Pectoralis major myocutaneous flap for reconstruction of circumferential pharyngeal defects. Ann Plast Surg 2013;71: 649-51.

9. Montemari G, Rocco A, Galla S, Damiani V, Bellocchi G. Hypopharynx reconstruction with pectoralis major myofascial flap: our experience in 45 cases. Acta Otorhinolaryngol Ital 2012;32:93-7.

10. Dubsky PC, Stift A, Rath T, Kornfehl J. Salvage surgery for recurrent carcinoma of the hypopharynx and reconstruction using jejunal free tissue transfer and pectoralis major muscle pedicled flap. Arch Otolaryngol Head Neck Surg 2007;133:551-5.

11. Demirtas Y, Yagmur C, Kelahmetoglu O, Demir A, Guneren E. Transaxillary-subclavian transfer of pedicled latissimus dorsi musculocutaneous flap to head and neck region. J Craniofac Surg 2010;21:771-5

12. Hayden RE, Kirby SD, Deschler DG. Technical modifications of the latissimus dorsi pedicled flap to increase versatility and viability. Laryngoscope 2000;110:352-7.

13. Amin AA, Rifaat M, Ellabban MA, Zedan M, Kamel M, Bassiouny M. Transaxillary thoracodorsal artery perforator flap: a versatile new technique for hypopharyngeal reconstruction. J Reconstr Microsurg 2014;30:397-404.

14. Heitmann C, Guerra A, Metzinger SW, Levin LS, Allen RJ. The thoracodorsal artery perforator flap: anatomic basis and clinical application. Ann Plast Surg 2003;51:23-9.

15. Hamdi M, Van Landuyt K, Hijjawi JB, Roche N, Blondeel P, Monstrey S. Surgical technique in pedicled thoracodorsal artery perforator flaps: a clinical experience with 99 patients. Plast Reconstr Surg 2008;121:1632-41.

16. Chiu ES, Liu PH, Friedlander PL. Supraclavicular artery island flap for head and neck oncologic reconstruction: indications, complications, and outcomes. Plast Reconstr Surg 2009;124:115-23.

17. Kokot N, Mazhar K, Reder LS, Peng GL, Sinha UK. The supraclavicular artery island flap in head and neck reconstruction: applications and limitations. JAMA Otolaryngol Head Neck Surg 2013;139:1247-55.

18. Pallua N, Machens HG, RennekampffO, Becker M, Berger A. The fasciocutaneous supraclavicular artery island flap for releasing postburn mentosternal contractures. Plast Reconstr Surg 1997;99:1878-84.

19. Piazza C, Taglietti V, Nicolai P. Reconstructive options after total laryngectomy with subtotal or circumferential hypopharyngectomy and cervical esophagectomy. Curr Opin Otolaryngol Head Neck Surg 2012;20:77-88
20. Li KK, Salibian AH, Allison GR, Krugman ME, Armstrong W, Wong $\mathrm{B}$, et al. Pharyngoesophageal reconstruction with the ulnar forearm flap. Arch Otolaryngol Head Neck Surg 1998;124:1146-51.

21. Rand RP, Lin EY, Wood DE. Total esophageal reconstruction using a tubed parascapular free flap. Ann Thorac Surg 2001;72:267-70.

22. Kim EK, Evangelista M, Evans GR. Use of free tissue transfers in head and neck reconstruction. JCraniofac Surg 2008;19:1577-82.

23. Yu P, Lewin JS, Reece GP, Robb GL. Comparison of clinical and functional outcomes and hospital costs following pharyngoesophageal reconstruction with the anterolateral thigh free flap versus the jejunal flap. Plast Reconstr Surg 2006;117:968-74.

24. Varvares MA, Cheney ML, Gliklich RE, Boyd JM, Goldsmith T, Lazor J, et al. Use of the radial forearm fasciocutaneous free flap and montgomery salivary bypass tube for pharyngoesophageal reconstruction. Head Neck 2000;22:463-8.

25. Yang G, Chen B, Gao Y. Forearm free skin flap transplantation. Nat Med J China 1981;61:139-42.

26. Song YG, Chen GZ, Song YL. The free thigh flap: a new free flap concept based on the septocutaneous artery. Br J Plast Surg 1984;37:149-59.

27. Nakatsuka T, Harii K, Asato H, Ebihara S, Yoshizumi T, Saikawa M. Comparative evaluation in pharyngo-oesophageal reconstruction: radial forearm flap compared with jejunal flap: a 10-year experience. Scand J Plast Reconstr Surg Hand Surg 1998;32:307-10.

28. Cho BC, Shin DP, Byun JS, Park JW, Baik BS. Monitoring flap for buried free tissue transfer: its importance and reliability. Plast Reconstr Surg 2002;110:1249-58.

29. Selber JC, Xue A, Liu J, Hanasono MM, Skoracki RJ, Chang EI, et al. Pharyngoesophageal reconstruction outcomes following 349 cases. J Reconstr Microsurg 2014;30:641-54.

30. Seidenberg B, Rosenak SS, Hurwitt ES, Som ML. Immediate reconstruction of the cervical esophagus by a revascularized isolated jejunal segment. Ann Surg 1959;149:162-71.

31. Righini CA, Bettega G, Lequeux T, Chaffanjeon P, Lebeau J, Reyt E. Use of tubed gastro-omental free flap for hypopharynx and cervical esophagus reconstruction after total laryngo-pharyngectomy. Eur Arch Otorhinolaryngol 2005;262:362-7.

32. Lorenz RR, Alam DS. The increasing use of enteral flaps in reconstruction for the upper aerodigestive tract. Curr Opin Otolaryngol Head Neck Surg 2003;11:230-5.

33. Fabian RL. Reconstruction of the laryngopharynx and cervical esophagus. Laryngoscope 1984;94:1334-50.

34. Jegoux F, Ferron C, Malard O, Espitalier F, Beauvillain de montreuil C. Reconstruction of circumferential pharyngolaryngectomy using a 'horseshoe-shaped' pectoralis major myocutaneous flap. J Laryngol Otol 2007;121:483-8.

35. Pierrel C, Bodin F, Schultz P, Dupret-Bories A. Semi-free forearm flap for pharyngeal-esophageal reconstruction after radiation therapy. Eur Ann Otorhinolaryngol Head Neck Dis 2015;132:101-3.

36. Komorowska-Timek E, Lee GK. Tube-in-a-tube anterolateral thigh flap for reconstruction of a complex esophageal and anterior neck defect. Ann Plast Surg 2014;72:64-6. 
37. Dodd AR, Goodnight JE, Pu LL. Successful management of cervicoesophageal anastomosis leak after microsurgical esophageal reconstruction: a case report and review of the literature. Ann Plast Surg 2010;65:110-4.

38. Gaur P, Blackmon SH. Jejunal graft conduits after esophagectomy. J Thorac Dis 2014;6 Suppl 3:S333-40.

39. Hanson RP, Chow TK, Feehan E, Eadie PA, Timon CT, Keogh S. Analysis of functional results and quality of life following free jejunal flaps for reconstruction after upper aerodigestive neoplastic resection: the St James's experience. J Plast Reconstr Aesthet Surg 2007;60:57782.

40. Laing TA, Van Dam H, Rakshit K, Dilkes M, Ghufoor K, Patel H. Free jejunum reconstruction of upper esophageal defects. Microsurgery 2013;33:3-8

41. Moradi P, Glass GE, Atherton DD, Eccles S, Coffey M, Majithia A, et al. Reconstruction of pharyngolaryngectomy defects using the jejunal free flap: a 10-year experience from a single reconstructive center. Plast Reconstr Surg 2010;126:1960-6.

42. Schneider DS, Gross ND, Sheppard BC, Wax MK. Reconstruction of the jejunoesophageal anastomosis with a circular mechanical stapler in total laryngopharyngectomy defects. Head Neck 2012;34:721-6.

43. Chang SY, Chen HC, Tang YB, Tan BK, Wei FC. Prefabrication of jejunum for challenging reconstruction of cervical esophagus. Plast Reconstr Surg 1999;104:2112-5.

44. Talbot SG, Cordeiro PG. Inverted, stapled J-pouch free jejunal transfer for reconstruction of the pharynx and esophagus. J Surg Oncol 2007;95:663-9.

45. Perrone F, Nitto A, Tang YB, Chen SH, Chen HC. Three uses of an extra length of jejunum in pharyngo-oesophageal reconstruction with free jejunal flap. J Plast Reconstr Aesthet Surg 2013;66:16-22.

46. Leu YS, Huang CM, Yang CC, Hsiao HT, Chang YC. Functional outcome following free ileocolic flap in total pharyngolaryngectomy. Acta Otolaryngol 2008;128:702-5.

47. Perez-Smith D, Wagels M, Theile DR. Jejunal free flap reconstruction of the pharyngolaryngectomy defect: 368 consecutive cases. J Plast Reconstr Aesthet Surg 2013;66:9-15.

48. Kim Evans KF, Mardini S, Salgado CJ, Chen HC. Esophagus and hypopharyngeal reconstruction. Semin Plast Surg 2010;24:219-26. 